\title{
RESULTADOS AL PRIMER AÑO DE APLICADA LA VACUNA RECOMBINANTE CUBANA ANTIHVB EN ESQUEMAS 012 Y 016 MESES
}

\author{
O. Juliao ', A. González², V. Ramirez ${ }^{3}$, M.C. Rojas ${ }^{4}$, A. Iglesias $^{5}$
}

\begin{abstract}
Los resultados obtenidos por el método inmunoenzimático cuantitativo de Abbott al primer año de completados los esquemas 012 y 016 meses, con la vacuna recombinante cubana contra la hepatitis viral $\mathrm{B}$, muestran la inmunogenicidad en los vacunados con los dos esquemas, viéndose que el $100 \%$ tienen seroprotección y el $97 \%$ de estos tienen valores $\geq 100 \mathrm{UI} / \mathrm{I}$ para ambos esquemas. En cuanto a los valores de las medias geométricas, observamos que no se evidencian disminuciones significativas con el esquema 012, pero sí con el esquema 016, por lo cual sugerimos el uso del esquema 012 , debido a su corta latencia, simetría y estabilidad de los valores de anticuerpos anti-HBs.
\end{abstract}

\section{INTRODUCCION}

Es de gran importancia hacer el seguimiento de la inmunogenicidad de las vacunas en el tiempo (1). En trabajos anteriores hemos descrito la cinética de producción de anticuerpos anti-HBs en cuanto a latencia y máximo de intensidad de respuesta en niños (2) y adultos ( 3 , 4). Teniendo en cuenta la importancia de conservar valores de 10 o más UI/I (seroprotección) (5). Por esta razón, programamos realizar las pruebas para determinar los niveles de anticuerpos anti-antígeno de superficie de hepatitis $\mathrm{B}$ al primer año de aplicada la vacuna recombinante cubana en esquemas 012 y 016 meses, en un grupo de funcionarios voluntarios del Instituto Nacional de Salud y del Ministerio de Salud de nivel central en Santafé de Bogotá, Colombia.

\section{MATERIAL Y METODOS}

A 75 voluntarios, 38 del esquema 012 y a 37 del esquema 016 meses, se les tomó muestra de sangre y se les determinaron los anticuerpos anti antígeno de superficie HVB por el método de Abbott cuantitativo cuando completaron el primer año de haber recibido su respectivo esquema, tres dosis.

La inmunogenicidad se midió de acuerdo con la metodología de estudio aplicada por nosotros (2-4); es decir, en categorías (seroprotección, hiperrespuesta) y medias geométricas. Las variables cualitativas (categorías) se evaluaron con la prueba de Chi cuadrado y las cuantitativas (valores individuales a la tercera dosis y al primer año), por el test de t de series apareadas, considerándose significativas aquellas diferencias que en tabla correspondieran a $\mathrm{p}<, 05$.

\footnotetext{
1 Asesor Epidemiologia, Instituto Nacional de Salud. Santafé de Bogota

2 Instituto Superior de Ciencias Médicas, La Habana, Cuba.

3 Centro de Ingeniería Genética y Biotecnología, La Habana, Cuba.

4 Grupo de Virología. Instituto Nacional de Salud. Santafé de Bogotá.

5 Director. INS.
} 


\section{RESULTADOS Y CONSIDERACIONES}

Los resultados se dan en número y porcentajes según categorías de valores ( $\mathrm{UI} / \mathrm{I}$ ) y en media geométrica (UI/I) (tablas 1 y 2 ).

Todos los sueros investigados, mostraron valores correspondientes a seroprotección, siendo el $97 \%$ de éstos mayores a $100 \mathrm{UI} / \mathrm{l}$ para los dos esquemas (012 y 016 meses), sin mostrar diferencias estadísticas significativas con su categorización pos-t terceradosis $p>0,05$ (tabla 1).

El análisis de las medias geométricas posttercera dosis y al primer año para cada uno de los esquemas, nos permite evidenciar que en el esquema 012 la media geométrica al año es superior a la obtenida post- terceradosis, por lo que el índice tercera dosis/primer año es inferior a $1(0,83)$. El análisis individual de series apareadas ratificó esta observación $(t=-3,8)$ para 37 grados de libertad $(p>0,05)$. Estos resultados evidencian que no existe dișminución de la respuesta inmune en este esquema, tomando como referencia lo que consideramos respuesta inmune máxima; es decir ,15 días después de terminado el esquema de vacunación.

El análisis para las medias geométricas en el esquema 016 permite señalar que la caída en valores es de 6,4 entre la tercera dosis y el primer año de terminado el esquema. Lacomparación individual de los sueros apareados, para 36 grados de libertad, fue de $t=14,2 p<0,05$; por lo tanto, la caída en los niveles de anticuerpos anti-HBs por esta prueba es significativa estadísticamente.

\section{CONCLUSIONES}

A partir de los resultados obtenidos podemos concluir que, si bien en el esquema 016 se obtienen valores de anticuerpos post-esquema superiores al esquema 012, los mismos disminuyen de manera significativa al año, no ocurriendo ésto con el esquema 012. Por lo tanto, nos permitimos sugerir la utilización de este esquema, por su simetría y corta latencia, como también por la persistencia de la respuesta inmune, medida al año.

TABLA 1. Inmunogenicidad al primer año vacuna recombinante cubana anti HVB; número y \% por categorias de valores esquemas 012 y 016 meses

\begin{tabular}{|c|c|c|c|c|}
\hline & & METODO CUANTITATIVO & ABBOTT & \\
\hline & $\begin{array}{l}\text { ESQUEMA } \\
\text { NUMERO }\end{array}$ & $\begin{array}{r}012 \\
\%\end{array}$ & $\begin{array}{l}\text { ESQUEMA } \\
\text { NUMERO }\end{array}$ & $\begin{array}{r}016 \\
\%\end{array}$ \\
\hline Valores de0 UI// & 0 & 0 & 0 & 0 \\
\hline Valores de $1.9 \mathrm{UI} / \mathrm{I}$ & 0 & 0 & 0 & 0 \\
\hline Valores de 10-99 UI/I & 1 & 3 & 1 & 3 \\
\hline Valores $>100 \mathrm{UI} / \mathrm{I}$ & 37 & 97 & 36 & 97 \\
\hline TOTAL & 38 & 100 & 37 & 100 \\
\hline
\end{tabular}

TABLA 2. Inmunogenicidad post tercera dosis y al primer año vacuna recombinante cubana anti HVB; media geometrica (UI/I) esquemas 012 y 016 meses.

\begin{tabular}{lcc}
\hline & METOdO CUANTITATIVO ABBOTT MEDIA GEOMETRICA (UI/I) \\
& ESQUEMA 012 & ESQUEMA 016 \\
\hline $\begin{array}{l}\text { Post tercera dosis } \\
\text { test " } \mathrm{t} \text { " } \mathrm{p}\end{array}$ & 890 & 3655 \\
grados de libertad & $\mathrm{t}=-3.8 \mathrm{p}>.05$ & $\mathrm{t}=14.2 \mathrm{p}<.05$ \\
Primer año & 37 & 36 \\
\hline
\end{tabular}




\section{SUMMARY}

An immunoassay analysis of the seroprotection achieved one year after vaccination with the Cuban recombinant vaccine anti-VHB, revealed immunogenicity in $100 \%$ of those vaccinated with the schemes 012 and 016 months and reached values $\geq 100 \mathrm{lU} / \mathrm{l}$ in $97 \%$ for both schemes. The geometrical media showed a significan reducttion with the 016 scheme but not with the 012 scheme. Consequently, we propose the use of the levels 012 scheme because of its short latency, simmetry and stability of the levels anti-HBs stability antibody

\section{AGRADECIMIENTOS}

Los autores agradecen la colaboración del personal del Ministerio de Salud y del Instituto Nacional de Salud que participaron en este estudio, así como a Biolehner Ltda. por ayuda.

\section{REFERENCIAS}

1. Rojas W. Inmunología. Novena edición MedeIlin: ClB; 1983,183

2. Juliao O. Inmunogenicidad de la vacuna Cubana recombinante contra HVB en niños de 1 a 10 años con esquema 012 meses. Biomédica 1993; 13:

3. Juliao O. Estudio de inmunogenicidad para dos vacunas recombinantes contra hepatitis $B$ comparando dos esquemas.Biomédica 1991; 11: 71-83

4 Hoyos AV. Hepatitis B Inmunogenicidad de la vacuna recombinante Cubana Anti-HBV en trabajadores de la salud vacunados sin seroprotección. Biomédica 1991; 11: $61-64$

5. Caroucé $\mathbf{A M}$, Jungers $\mathbf{P}, \mathbf{y}$ col. Hepatitis $B$ vaccine in dialysis patients. $\mathrm{N}$ Engl $\mathrm{J}$ Med 1984; 311-1515. 


\section{B।OMED ICA}

\section{INSTRUCCIONES PARA LOS AUTORES}

BIOMEDICA: Revista del Instituto Nacional de Salud, eminentemente científica, publicación trimestral.

Está amparada por la Resolución No. 03768 de 1981, emanada del Ministerio de Gobierno.

Ninguna publicación, nacional o foránea, podrá reproducir o traducir sus artículos o resúmenes, sin previa autorización escrita del editor.

Ni la Revista, ni el Instituto asumen responsabilidad alguna por los puntos de vista expresados por los autores.

La revista no publicará ningún tipo de propaganda comercial. Los nombres de equipos, materiales y productos manufacturados que eventualmente puedan mencionarse, no implican recomendación o propaganda para su uso y sólo se mencionarán como identificación genérica.

1. BIOMEDICA: acepta para publicación artículos, fruto de la investigación, que contribuyan a ampliar los conocimientos sobre biomedicina, realizados tanto en el Instituto Nacional de Salud como en cualquier otro centro de investigación.

2. BIOMEDICA publicará la siguiente categoría de trabajos:

a. Artículos originales: son trabajos inéditos derivados de una investigación biomédica. Se exceptúan de esta norma aquellos trabajos de investigadores del Instituto que hayan sido ya publicados en revistas extranjeras de reconocida prestancia, previo consentimiento escrito del autor y de la respectiva revista.

b. Comunicaciones breves: son trabajos derivados de una investigación básica, epidemiológica o clínica cuyo conocimiento rápido se considera de gran importancia.

c. Informes técnicos: son documeritos derivados de una reunión de expertos sobre un tema específico.

d. Actualizaciones: son trabajos que, apoyados en bibliografía reciente destacan los avances más significativos de un problema específico.

e. Memoranda: son documentos muy sobrios que exponen la situación de un aspecto específico.

f. Revisión de temas: son publicaciones densas que revisan exhaustivamente un tema determinado con la más amplia bibliografía posible.

g. Comentarios bibliográficos: son escritos breves, críticos, sobre libros de biomedicina recientemente publicados que, por su impacto, merecen ser comentados.

h. Cartas al editor: son cartas de los lectores solicitando aclaraciones o presentando comentarios sobre material publicado en la Revista.

3. Todo material propuesto para publicación será revisado por el Comité Editorial. El Editor informará a los autores, sobre la recepción de los trabajos, y sobre la decisión final que se tome.

4. La revista se reservará el derecho de aceptar o rechazar los artículos y podrá hacer sugerencias que tiendan a mejorar su presentación. Para un mejor cumplimiento de esta función el Comité Editorial consultará a especialistas en la materia. 
5. Los originales de los artículos publicados permanecerán en los archivos de la revista; aquellos no aceptados, serán devueltos a sus autores.

6. El autor principal recibirá libre de costo 5 ejemplares de la revista y 20 separatas de su trabajo.

7. Todo trabajo que se desee publicar en la Revista Biomédica deberá ser enviado al Editor de la Revista, Oficina de Publicaciones, Instituto Nacional de Salud, Avenida Eldorado Cra. 50 Zona 6 o Apartado aéreo 80080 y 80334 , Santafé de Bogotá D.C., Colombia.

8. BIOMEDICA, sólo considerará para publicación aquellos trabajos que llenen los siguientes requisitos:

a. Ser escritos a máquina, doble espacio, papel tamaño carta, páginas numeradas, dejando un margen de $4 \mathrm{cms}$ a la izquierda y $2 \mathrm{cms}$ a la derecha.

b. Presentar un (1) original y dos (2) copias.

c. El trabajo debe venir organizado así:

Hoja separada con un título conciso. Puede tener un subtitulo. Autores con nombre, inicial del segundo nombre y apellidos, seguido de un asterisco que indicará al pie de la página, la posición académica, institución, ciudad y país.

En hoja separada un resumen en español en donde se enfaticen los aspectos más relevantes del trabajo.

En hoja separada un resumen en lengua inglesa que tenga el mismo contenido del resumen en español.

Contenido, introducción, materiales y métodos, resultados, discusión, agradecimientos y bibliografía.

Las fotografías deben venir en blanco y negro en papel brillante. Biomédica no publica fotografías en colores, salvo excepcionales circunstancias a juicio del Comité Editorial. Los cuadros, gráficos y figuras deben presentarse en dibujo, tinta negra, tamaño proporcional: para una columna $7.7 \mathrm{cms}$ de ancho y para media página $7.7 \mathrm{cms} \times 10.3 \mathrm{cms}$ o página entera $15.5 \mathrm{cms} \times 20.5 \mathrm{cms}$, en hoja separada la leyenda correspondiente.

La bibliografia debe venir señalada en el texto secuencia!mente con números, que corresponden al listado final. Para la correcta transcripción de la bibliografía. Biomédica se acoge a los requisitos unificados para trabajos presentados a revistas Biomédicas del Comité Internacional de editores de revistas médicas. Acta Médica Colombiana 1987; 12: 361.

Deben tenerse en cuenta los siguientes aspectos: artículos de más de tres autores se citan sólo los tres primeros, seguidos de la palabra latina et al. El título completo del artículo, el nombre abreviado de la revista, el año, el volumen y la primera página.

A manera de ejemplo citamos:

1. Nair CP. Rapid staining of intestinal amoeba on wet mounts. Nature 1953; 172: 1051.

2. Kim HW, Arrobio JO, Brandt CD, et al. Epidemiology of respiratory syncitial virus infection in Washington DC. Am J Epidemiol 1973; 98: 216.

3. Kennt GE. Mycoplasmas. Chapter 36, in Lennette EH, Balows A, Hauser Jr W J, Shadomy H J Eds. Manual of Clinical Microbiology fourth ed. Washington D C. American Society of Microbiology 1985: 407-411. 